\title{
Spatial Character and Backflow Pattern of High-Level Returned Talents in China
}

\author{
Haining Jiang $\mathbb{D}$ \\ College of Geography and Environmental Sciences, Zhejiang Normal University, Jinhua 321004, China \\ Correspondence should be addressed to Haining Jiang; jhn841263@163.com
}

Received 17 August 2020; Revised 30 December 2020; Accepted 21 January 2021; Published 8 February 2021

Academic Editor: Alejandro F. Villaverde

Copyright (c) 2021 Haining Jiang. This is an open access article distributed under the Creative Commons Attribution License, which permits unrestricted use, distribution, and reproduction in any medium, provided the original work is properly cited.

\begin{abstract}
Attractions of overseas high-level returned talents have become a widely practiced talent policy, and the spatial structures of city-related interactions are drawing the attention of researchers from various fields. China is particularly an interesting case in point, as it has moved toward an innovation-oriented economy. Based on the movement trajectories of 2,846 returnees in a program entitled "Young Thousand Talents Plan" during 2011-2016, this paper identifies three city types in China: national core city, regional excellent city, and regional special city. Subsequently, this paper employs spatial visualization and qualitative interviews. This paper also goes on to show that the national core cities that possess dense research resources that coincide with premium life conditions and have objectively more favorable conditions, wider opportunities for attracting highly qualified specialists. Moreover, the backflow pattern can be divided into circle route and linear route, which is driven by social proximity and innovation context.
\end{abstract}

\section{Introduction}

The world has progressed from competition among firms for markets and the workforce to cities for creative professionals [1]. The huge gap in talent demand makes many of countries turn their eyes abroad, recruiting overseas high-level talents worldwide with attractive policies and salaries [2,3]. A global city rises in response to the time and conditions. These are the strategic migration destination of overseas high-level returned talents and are interconnected in the dynamic process of knowledge production, innovation accumulation, and network extension [4]. Since the 1980s, the transnational flow of high-level talents has become a hotspot in the study of population migration in academics [5].

With the acceleration of globalization and the improvement of China's economic development, China is expanding and gradually developing into an innovation-oriented economy that depends not only on foreign technology input but also on domestic knowledge building and improvement of innovation performance [6]. Increasing input in science, technology, and $\mathrm{R} \& \mathrm{D}[7,8]$ is fueled by public and private investment from multinationals [9]. In this context, China is no longer the world's largest brain drain, but the most desirable innovation destination, remolding competitive abilities in international situations $[8,10]$. Corresponding with the booming innovation outcomes and the competitiveness of the Chinese economy, there are a number of major urban centers, characterized by resource hubs for managing multiple flows of global capital, multinational firms, human resources, and innovation knowledge. These major urban centers are becoming global cities [11, 12]. Considering the dominant advantages of global cities as premium choices of employment, it should come as no surprise that most returnees choose them as their relocation destinations $[13,14]$. The degree of attraction of high-level talents can be a direct reflection of the status of a particular city in the world economic and urban system $[15,16]$.

In this context, the Chinese overseas high-level returned talents have increasingly been the subject of scholarship aimed at understanding talent flow, migration, Chinese cities, and innovation systems [17]. Concerning existing literature, there has been a very limited concrete empirical assessment of circular migration [18], and the results are somewhat ambiguous and contradictory in some respects due to the methodological differences. One important difference relates to the source of data investigated. For example, the data of 
countries at the provincial level may lead to results that have disagreements with those obtained from data of city levels, while similar differences also occur in the level of data aggregation and analysis. Spatial analyses are usually carried out at the level of either province or city, and in these cases, the meaning of "regional" versus "national" characteristics is obviously different. A second important divergence concerns the interactive mechanism between skilled international migration and cities [19]. Questionnaire surveys, in-depth interviews, and qualitative analysis have been widely adopted. The data derive from representative samples, in-depth accounts of specific universities, and/or firms involving senior overseas returnees $[11,20]$, which is mainly concentrated in the fields of pedagogy and demology [21]. The research on backflow structure and pattern is inadequate and especially scarce from a geographical perspective.

In order to examine the purpose of the backflow structure and pattern of China high-level returned talents, it is necessary to select a database with strong involvement of high-level overseas talents and domestic backflow organizations, including research institutes, universities, and stateowned and privately owned firms. The results will contribute to a better understanding of the spatial structure of China in particular and of emerging economies in general. This paper thus focuses on the migration trajectories of recruits in the "Young Thousand Talents Plan" (1000 plan, in short), which provides the most interesting case for the proposed analysis. First, in line with a plan to prevent China's brain drain, the 1000 plan is represented by a group of highest-qualified overseas human capital. Second, the selected candidate and its relocation decision is a process shaped by political goals and the economic process in China, reflecting the enormous structural situation in the country.

By examining graphical mapping and social analysis on the backflow structure of China overseas high-level talents in the 1000 plan, this paper addresses the following research questions: (1) What are the backflow structural characteristics of China overseas high-level returned talents? (2) What are the backflow patterns and their driving forces?

This paper provides a visualization and mechanism analysis of a backflow structure based on the complete data provided by the official website of the 1000 plan. It is organized as follows: Section 2 describes the framework that drives the empirical analysis. Section 3 provides a brief introduction to the research design and data source. Section 4 then focuses on the empirical analyses testing the backflow structure and provides a reasonable explanation of the results. Finally, in Section 5, conclusions and implications for further research are discussed.

\section{Spatial Configurations}

In the competition for talent resources, overseas high-level returned talents can be viewed as a crucial process. The return location does matter for the agglomeration and circulation of talents. These selected cities in turn increase their competence in high-level areas and experience economic growth. Particularly, the overseas high-level returned talents and the already involved interplay of domestic and foreign players in multispatial scales are an important process of both contemporary globalization and innovation $[22,23]$. They are generally embedded in a broader network at various spatial scales, evolving sociospatial relations through individual education, career trajectories, and personal relationships [24]. It can be clearly seen that concentrated returnee talent and the cross-city movement can improve the connectivity of a city.

To help introduce a simple typology, this study proposes a combination of two spatial logics: the territorial approach (cities as industry agglomerations and/or bases) and the innovation theory (cities' hierarchy in China national innovation system). Figure 1 presents three types of cities in the process of relocation decisions: (1) national core city (expressed in "1" in Figure 1) that occupies central positions within a city network, which possess the key characteristics of a knowledge hub and has the potential to disseminate knowledge internally through different channels and to stimulate learning; (2) regional excellent city (expressed in " 2 " in Figure 1) is a regional centered model that has well-functioning transportation and communication infrastructures for international flows of people and ideas, which occupy the second tier in the Chinese science and technology system and/or urban administrative system, and (3) regional special city (expressed in " 3 " in Figure 1) that host China's strongest industrial agglomeration and/or research organizations but occupies peripheral positions in China's hierarchical science and technology system and/or urban administrative system. It is no doubt that the return-migration decision of overseas high-level talents is due to the combination of a dynamic interface of professional and personal factors, that is, the result of rethinking the social advantages versus professional benefits from living in different cities. This mainly involves two driving factors: (1) innovation context and (2) social proximity.

2.1. Innovation Context. Context is the economic and institutional environments that may or may not affect the behavior of an individual in the process of making and fulfilling decisions. Understanding the context in which decisions are made has attracted much scholarly attention in the field of economic geography. There are numerous factors behind context and location choices of overseas high-level talents [21], which are often positively correlated with China's hierarchical science and technology system.

During the last fifty years, China has reformed its science and technology system, which was once designed in accordance with the Soviet concept and has been transformed to meet the expectations of a modernized economy. To be specific, in the early 1980 s, public research institutes carried out $\mathrm{R} \& \mathrm{D}$, while universities were restricted to education. State-owned enterprises were then expected to collaborate with research institutes that coincided with their technological needs [25]. With the reform of China's scientific sector, significant restructuring of public research institutes, and a broadening of functions for universities, the former patterns of technological advancement have undergone 


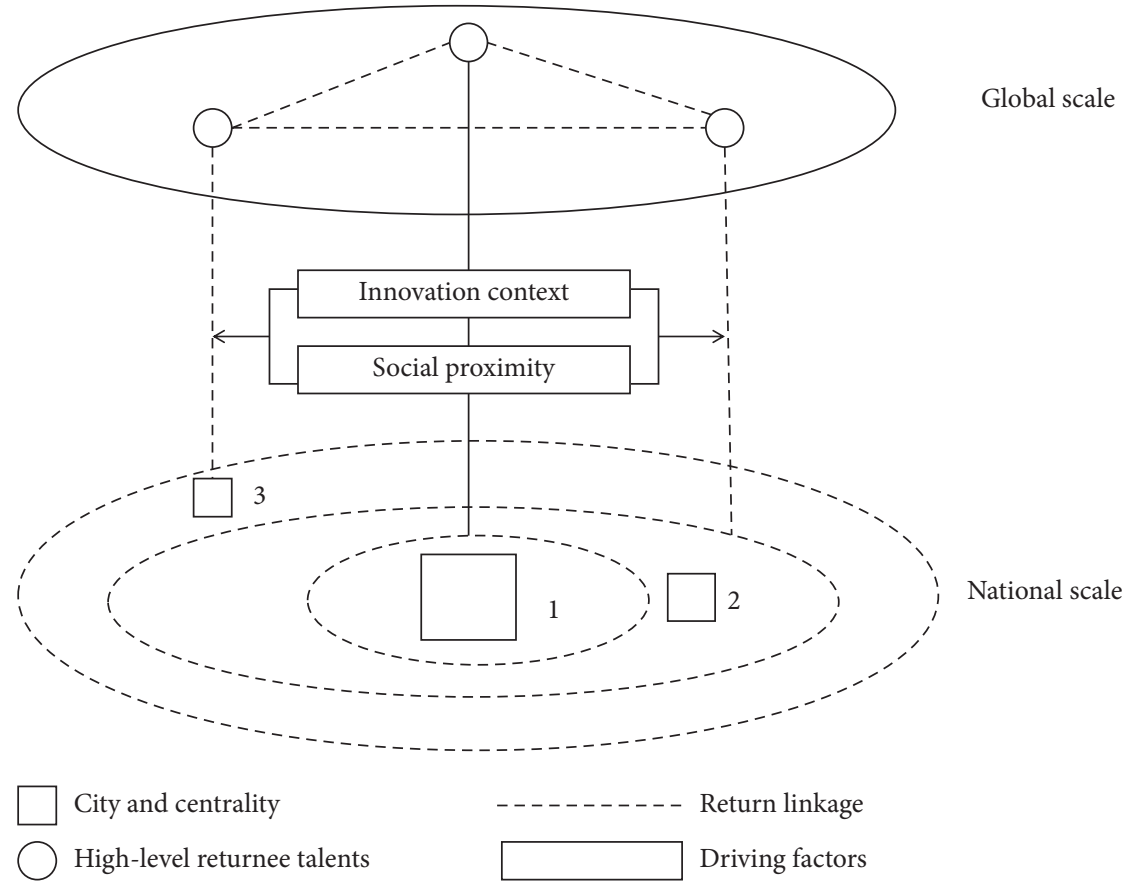

FIgURE 1: A typology of hierarchical cities driven by China overseas high-level returned talents.

considerable changes [26]. Thus, China has built up leading research universities that are capable of carrying out basic as well as complex R\&D. Moreover, recent research has pinned one vital notion that concerns the spatial character of China's science and technology system. That is, it has a strong hierarchical order, with Beijing and a handful of other cities/regions in the medium ranks, dominating the national system [7].

Generally speaking, due to the positive correlation with the availability and thickness of resource endowment, the city hierarchy in China's science and technology is a crucial factor and is expected to influence the backflow potential of their city being chosen by talented returnees. These cities have a highly positive correlation with better life quality, ample resources, premium research organizations, prospective $\mathrm{R} \& \mathrm{D}$ resources, technological policy, and career platform [21].

2.2. Social Proximity. From a cultural perspective in China, especially in terms of kinships, alumni (schoolmates or classmates), birthplace, and so on, social proximity is likely to constrain and enable the spatial decision of high-skilled and professional migration [21, 27]. For example, Gu et al. (2019) employed the data from the Chinese national one percentage population sample survey and pointed out that social networks exert a vital role in location choice [28]. Based on the existing research, this study theorizes two types of social proximity that can have a significant impact on backflow style toward a city choice [21].

One of the frequently examined factors is the alumni connection [29]. Prior research suggested that most of the high-level returned talents who had graduated from the top universities all over the world had domestic education experiences, which can be part of primordial ties. Research on the return choice of social factors has shown empirical evidence that the alumni community plays an essential role in the return choice. This choice is usually heavily influenced at the beginning of coming into a new environment and requires personal connections to change the natural instinct of alumni to return to the familiar [8].

In addition, the birthplace is attached to emotional gains and endows an inevitably cultural and social comparative advantage to determine the choices, such as being close to one's friends/relatives [30]. For most high-level returned talents, the experience in a foreign country brings with it unfamiliar environments and societies, which may in turn create more emotional needs with parents, spouse, friends, and other relatives [31]. In the context of China, some highlevel returned talents comply with their parents' wishes to return home because of filial obligations [29, 32]. For example, Xue (2012) employed a comparative analysis among birthplace, workplace, and where one studied, which suggested that social ties to one's birthplace play one of the most important factors in the decision-making of relocation choices of high-level returned talents [33].

\section{Materials and Methods}

In the so-called "war" or "race" for talents, the 1000 plan was established in December 2008 and was monitored by representatives from several central government bodies, with the aim of bringing back distinguished professors and scholars, highly skilled engineers, and entrepreneurs to China. The plan consists of several categories that offer significant financial support to high-level overseas scientists who decide to relocate to China for conducting research in high-tech industries or in new fields of the exciting frontier 
of science. In participating in major Chinese scientific projects, key laboratories, state-owned enterprises, stateowned financial institutions, high-tech development zones, and industrial parks, China offers scientists a wide range of incentives to relocate in its major cities. Toward this objective, this paper uses the database from young talents from the website http://www.1000plan.org, which is vital to China's talent program.

3.1. Data Sources. Data preparation involves several steps that are listed as follows. First, the basic qualification requirements of eminent overseas young scholars are as follows: the candidate should be below 40 years of age and possess a doctoral degree in natural sciences, engineering, or technology. In addition, they should have at least three years of postdoctoral research or professional experience in popular overseas universities, research institutions, or enterprises.

Second, the Young 1000 plan commenced in 2011; the selection procedure is rigorous and has a certain publication periodicity; therefore, the results are not published every year. Combined with the research goal, this paper gives priority to the dynamics of network structure and the year window. This window commences from the planned start of 2011 to the end of 2016. In sum, there were eight announcements, with 2,846 young talents in total.

Third, the spatial network of the talents can be attributed to the cities in which they are from. Hometown, education, and career path are all influential units of geographical analysis, defining what makes up local, national, and global. Moreover, some missing individual information is enhanced and collated through consultations over telephone and email.

Fourth, as part of the research, five selected talents were included in the experimental phase. Information was obtained from in-depth semistructured interviews from December 2018 to December 2019. The face-to-face surveys lasted anywhere between half-an-hour and an hour. The interviews were conducted in Mandarin and were recorded using tape and transcribed into text word by word. As a supplement to established interview transcription, additional information was accessed online and from books and periodicals.

As a preliminary finding (see Table 1), it can be inferred that, in line with previous studies, the premium choice of most of the overseas high-level returned talents was the university, accounting for an approximately $83 \%$ share; primarily in the fields of Biological Science, Engineering \& Materials Science, Mathematical \& Physical Science, and Chemistry. China's cities differ greatly in terms of research resources, showing that the spatial configuration is highly clustered around certain cities: Beijing and Shanghai are clearly leading with respect to the location of overseas high-level returned talents (677 for Beijing; 466 for Shanghai), followed by Wuhan, Nanjing, Hangzhou, Hefei, Guangzhou, and Chengdu, whose sum of professionals is between 201 and 112 .

3.2. Study Method. The empirical analysis consists of two aspects: spatial visualization and qualitative interviews.
First, this paper visualizes the candidates' migration trajectories from their birthplace, study, and work cities in China and abroad to relocation choice and subsequent work changes. Despite certain shortcomings, the return location has developed into a standard tool in the empirical literature. (1) Dynamic places can fully reflect the need for socioeconomic development, which leads to the mobility of talented personnel in different cities. (2) This indicator hits close to the core of an important network formation and changing process. Talents can be assumed to share knowledge and innovation thoughts in the same domains, building a collaboration pipeline and bringing about the dynamics of the city system. (3) This approach shows how cities worldwide are linked.

Second, location does matter for the mobility and circulation of talent. Attractiveness of a cosmopolitan living environment, quality of life, business, employment, and educational opportunities all play a crucial role in bringing back talent to Chinese cities. This paper uses open and axial coding to determine relevant concepts in the data and then group them into categories. Open and axial coding has proven to be the most applicable method in analyzing these driving factors. Using this coding, it was possible to access five selected talents that formed the empirical cases (see Table 2). The course of these interviews can be categorized into three sections: (1) detailed information on the movement path and its influencing factors, (2) information of government support on innovation and involved scientific research, and (3) basic status of life in the selected city and corresponding evaluations, such as city infrastructure, R\&D support, and restrictions.

\section{Results}

4.1. Actor Composition. In order to assess the dimensions of a cooperation network driven by the overseas high-level returned talents, the study categorizes the corporative ties of returnees in accordance with the organization that they graduated from and worked for. In the actor composition of the return choice of China's organizations (see Table 3), the top-tier universities in Beijing, Shanghai, Wuhan, and Nanjing have turned out to be the key actors, holding about $60 \%$ of the overseas high-level returned talents focused on the top 20 first-class universities. The above trend is extremely obvious in that $42.45 \%$ of those returnees are dominated by the top 10 actors. Hence, we can duly say that a large number of cities with prestigious research organizations might be an unintended consequence of exacerbating the national uneven tendency of high-degree innovative resources.

Regarding the characteristics of the overseas actors' centrality, the paper notably finds that $52.32 \%$ had educational and work experience in the USA, 5.90\% in the UK, $12.39 \%$ in Europe (other than the UK), $10.61 \%$ in Asian countries, and $2.99 \%$ in Australia. Moreover, in terms of the number of actors, the Chinese professional primarily had overseas experience in American elite universities: Harvard University, Stanford University, Massachusetts Institute of Technology, and the University of California. 
TABle 1: Descriptive statistics of location choice.

\begin{tabular}{lccccc}
\hline Subjects & \multicolumn{3}{c}{ Work unit } & Top 3 locations \\
& University & Research institute & Enterprise & Sum \\
\hline Mathematical \& Physical Science & 357 & 83 & 1 & Beijing (163), Shanghai (81), and Hefei (44) & 441 \\
Chemistry & 311 & 71 & 10 & Beijing (62), Shanghai (60), and Nanjing (30) & 392 \\
Environmental \& Earth Science & 191 & 52 & 0 & Beijing (72), Nanjing (28), and Wuhan (26) & 243 \\
Information Science & 273 & 24 & 0 & Beijing (57), Shanghai (46), and Chengdu (28) 297 \\
Biological Science & 587 & 169 & 0 & Beijing (176), Shanghai (174), and Hangzhou (63) 756 \\
Engineering \& Materials Science & 631 & 81 & 5 & Beijing (147), Shanghai (87), and Nanjing (60) 717 \\
\hline
\end{tabular}

Table 2: Profile of five cases.

\begin{tabular}{lcccc}
\hline Case & Backflow year & Subject & Backflow location & Interview time \\
\hline A & 2018 & Biological Sciences & Shanghai & $2019-09-20$ \\
B & 2015 & Engineering \& Materials Science & Xi'an & $2018-10-08$ \\
C & 2015 & Information Science & Chongqing & $2019-07-20$ \\
D & 2016 & Mathematical \& Physical Science & Beijing & $2019-01-30$ \\
E & 2012 & Engineering \& Materials Science & Suzhou & $2019-12-01$ \\
\hline
\end{tabular}

TABLE 3: Spatial structure of top 20 important actors and overseas organizations.

\begin{tabular}{|c|c|c|c|c|c|c|c|}
\hline \multirow{2}{*}{ Rank } & \multicolumn{3}{|l|}{ Return choice } & \multicolumn{4}{|c|}{ Overseas experience } \\
\hline & Actor & Location & Sum & Actor & Country & City & Sum \\
\hline 1 & Peking University & Beijing & 160 & Harvard University & USA & Boston & 82 \\
\hline 2 & $\begin{array}{c}\text { University of Science and Technology of } \\
\text { China }\end{array}$ & Hefei & 160 & Stanford University & USA & Palo Alto & 75 \\
\hline 3 & Zhejiang University & Hangzhou & 159 & Massachusetts Institute & USA & Boston & 68 \\
\hline 4 & Tsinghua University & Beijing & 157 & $\begin{array}{c}\text { University of California, Los } \\
\text { Angeles }\end{array}$ & USA & Los Angeles & 48 \\
\hline 5 & Shanghai Jiaotong University & Shanghai & 128 & $\begin{array}{c}\text { University of California, } \\
\text { Berkeley }\end{array}$ & USA & Berkeley & 47 \\
\hline 6 & Nanjing University & Nanjing & 105 & $\begin{array}{l}\text { Nanyang Technological } \\
\text { University }\end{array}$ & Singapore & Singapore & 47 \\
\hline 7 & Fudan University & Shanghai & 103 & Yale University & USA & New Haven & 45 \\
\hline 8 & SunYat-Sen University & Guangzhou & 87 & Columbia University & USA & New York & 35 \\
\hline 9 & $\begin{array}{c}\text { Huazhong University of Science and } \\
\text { Technology }\end{array}$ & Wuhan & 86 & National Institutes of Health & USA & Bethesda & 34 \\
\hline 10 & Wuhan University & Wuhan & 63 & National University of Singapore & Singapore & Singapore & 32 \\
\hline 11 & Shanghai Institutes for Biological Sciences & Shanghai & 61 & University of Pennsylvania & USA & Philadelphia & 31 \\
\hline 12 & Tongji University & Shanghai & 57 & University of Michigan & USA & Michigan & 30 \\
\hline 13 & $\begin{array}{c}\text { South University of Science and } \\
\text { Technology }\end{array}$ & Shenzhen & 52 & University of Hong Kong & China & Hong Kong & 26 \\
\hline 14 & Sichuan University & Chengdu & 51 & $\begin{array}{c}\text { University of California, San } \\
\text { Diego }\end{array}$ & USA & San Diego & 26 \\
\hline 15 & $\begin{array}{c}\text { University of Electronic Science and } \\
\text { Technology }\end{array}$ & Chengdu & 51 & Northwestern University & USA & Evanston & 26 \\
\hline 16 & Xiamen University & Xiamen & 47 & Purdue University & USA & $\begin{array}{l}\text { West } \\
\text { Lafayette }\end{array}$ & 25 \\
\hline 17 & Xi'an Jiaotong University & Xi'an & 46 & Cambridge University & England & Cambridge & 23 \\
\hline 18 & Suzhou University & Suzhou & 39 & $\begin{array}{l}\text { California Institute of } \\
\text { Technology }\end{array}$ & USA & Pasadena & 23 \\
\hline 19 & $\begin{array}{c}\text { Beijing University of Aeronautics \& } \\
\text { Astronautics }\end{array}$ & Beijing & 38 & Los Alamos National Laboratory & USA & Los Alamos & 23 \\
\hline 20 & $\begin{array}{c}\text { Tianjin University } \\
\text { Sum }\end{array}$ & Tianjin & $\begin{array}{c}36 \\
1696\end{array}$ & University of Texas at Austin & USA & Austin & $\begin{array}{c}21 \\
767\end{array}$ \\
\hline
\end{tabular}

4.2. The Backflow Structure. The centrality, indicated by the size of the nodes, is the extent to which a city is essential for channeling information, to identify key cities in the network. Figure 2, in order to produce high quality, only demonstrates those cities linked to more than five other cities. The study can therefore draw up the following conclusions: the city map shows Beijing as a significant core-pillar to the entire structure and Shanghai, Nanjing, and Wuhan as three subpillars, involving 


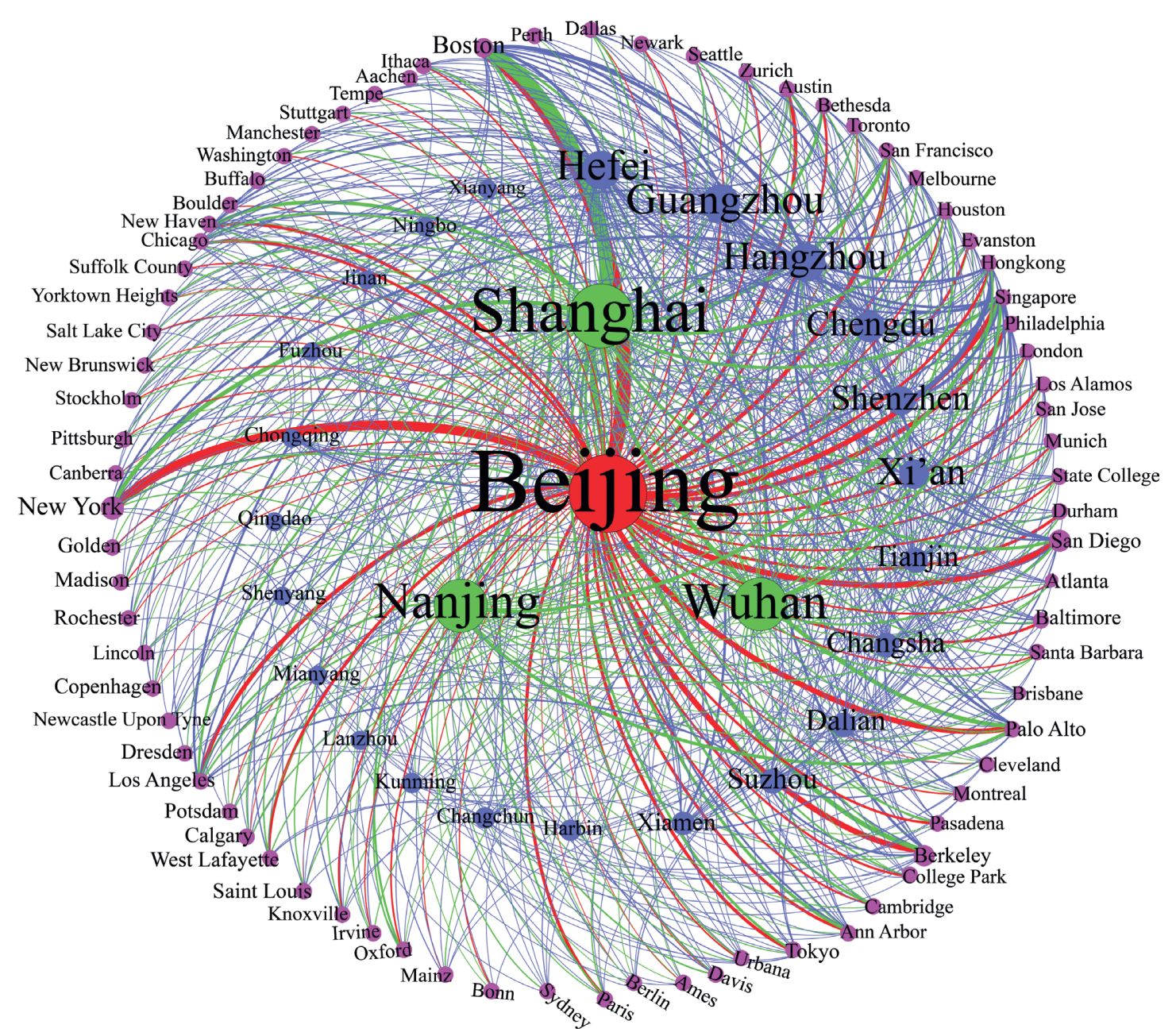

Figure 2: Centrality visualization of the global city from 2011 to 2016.

440 city nodes, with the most important overseas regions being North America, Western Europe, Japan, Singapore, and Australia. The nine most frequent links between two cities are Beijing-Boston (56), Shanghai-Boston (53), Beijing-New York (36), Beijing-Berkeley (21), Beijing-San Diego (21), Beijing-Palo Alto (20), Beijing-Singapore (19), Shanghai-Berkeley (17), and Beijing-Philadelphia (16).

Apparently, three types of cities driven by the relocation of China high-level returned talents will appear: national core city, regional excellent city, and regional special city (see Table 4). Generally, Beijing, Shanghai, Nanjing, and Wuhan are considered as the national core city, which have many top-tier universities and research institutions and easily gain access to a large-scale knowledge pool. These advantages tend to dominate the location choice of overseas high-level returned talents. The regional excellent city mainly involves 23 cities, such as Hefei, Guangzhou, Hangzhou, Chengdu, Shenzhen, and Xi'an. By contrast, the cities which host China's strongest industrial agglomeration and/or research organizations, such as Xianyang (Shaanxi Province, Northwest Agriculture \& Forestry University) and Mianyang (Sichuan Province, China Academy of Engineering Physics), are located at the peripheral level of the China's science and technology systems. It should be emphasized that the China Academy of Engineering Physics is the primary design laboratory for Chinese nuclear weapons and over $70 \%$ of the overseas high-level returned talents, who chose Mianyang as relocation, work in the institute. In Xianyang, there are eight overseas high-level returned talents and all of them work in the Northwest Agriculture \& Forestry University.

4.3. The Backflow Patterns. As far as the overseas high-level returned talents are concerned, they participate in various high-level talent flow programs and related research grants created by the central and/or local governments. Many talents have had the experience of studying abroad before returning and are encouraged to utilize the advantage of their professional knowledge, to engage in collaboration with the emigrating countries, to conduct professional and academic exchanges, and to establish channels or linkages. This section focuses on addressing the backflow patterns of China overseas high-level talents, which is conducted and described as follows. We selected five high-level returned talents and then identified their backflow patterns, by exploring the driving mechanism (see Figure 3 ). The 5 interviews show two interesting backflow patterns: B, C, and D 
TABLE 4: City hierarchical structure in China.

\begin{tabular}{lcc}
\hline Type of city & Number & Cities example \\
\hline National core city & 4 & Beijing, Shanghai, Nanjing, and Wuhan \\
Regional excellent city & 23 & Hefei, Guangzhou, Hangzhou, Chengdu, Xi'an, and so on \\
Regional special city & 25 & Mianyang, Xianyang, and so on \\
Sum & 52 &
\end{tabular}

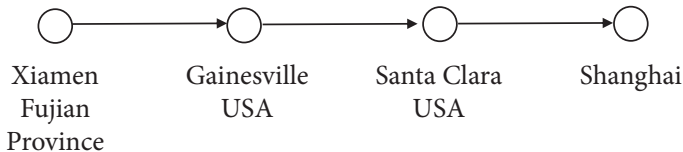

Case A

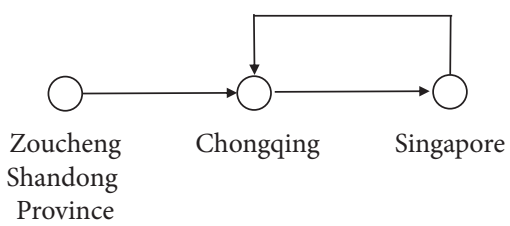

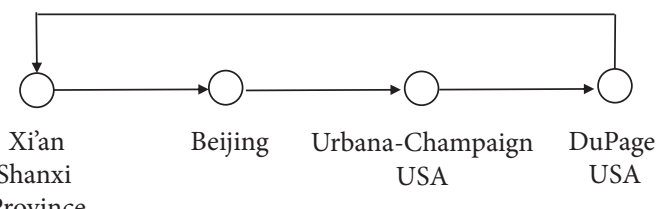

Case B

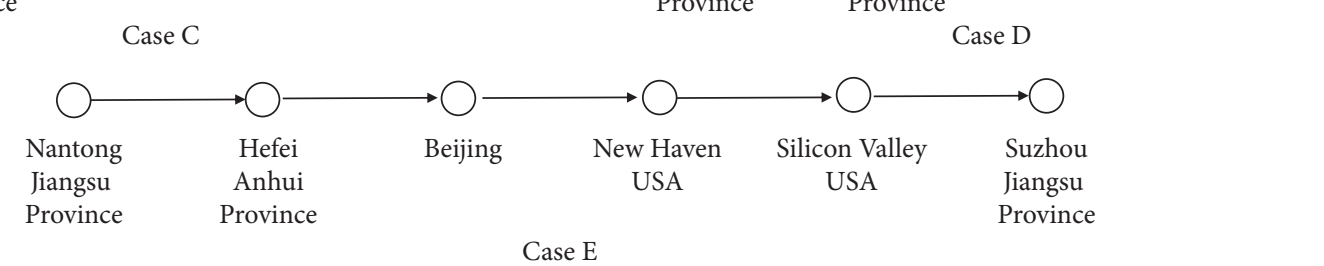

FIGURE 3: Backflow character formed by the migration tracks of five talents.

are circle routes while $\mathrm{A}$ and $\mathrm{E}$ are city explorers with a linear route.

A majority of Chinese experts have a common background, namely, bachelor and/or postgraduate phases in China, and more than three years of overseas study and work, predominantly in developed countries. Generally speaking, $90 \%$ of returnees have received a doctoral title from overseas universities and they have several years of work experience, while $10 \%$ of returnees are domestic scientists without foreign degrees and acquired five years of overseas experience either by working or through visiting programs. The study aims to find the relationships between these identified factors. Data analysis was supported by a coding procedure from the interviewees' transcripts and other supplementary materials. Finally, 21 codes were generated, and then the paper was collected and classified into six categories that can summarize the dynamics and its backflow structure of China overseas high-level talents from the perspectives of case studies (see Table 5).

There is no doubt that the return-migration decision of overseas high-level young talents is heavily influenced by professional and personal factors. These factors often result in the balancing/rethinking of innovation context versus social proximity of the relocation city in China. Based on the above analysis, the study combines the city's type, its backflow mechanisms, and its patterns to create Figure 4 .
In general, the circle pattern builds on a series of formal relationships. The talents usually return back to a prior circumstance to minimize the risk of failure and to realize the personal development within a reasonable time course. Therefore, the circle pattern tends to rely much more on social proximity, especially with respect to the parent university. Meanwhile, these backflow cities can also have certain advantages, such as developed infrastructure facilities, a high quantity of high-level universities and research institutions, a good cultural environment, and/or a highly developed economy.

Comparatively speaking, the linear pattern is mainly related to new city explorers. These overseas high-level returned talents normally focus on the factors associated with innovation context and city amenity, such as personal development, high level of income, children's education, and science research cooperation. It supports the notion that linear patterns, generally speaking, may give priority to innovation context over social proximity, and that they would rather choose distant top-tier research organizations than secondary ones in local city and/or provinces. By investigation and interview, we found that a large number of talents, whose hometowns were the second- and third-tier cities, tried to enter higher-level cities to change the shortage of innovation resources. In addition, social relationship networks usually still played an important role in attracting high-level returned talents backflow. 
TABLE 5: The process of coding procedure.

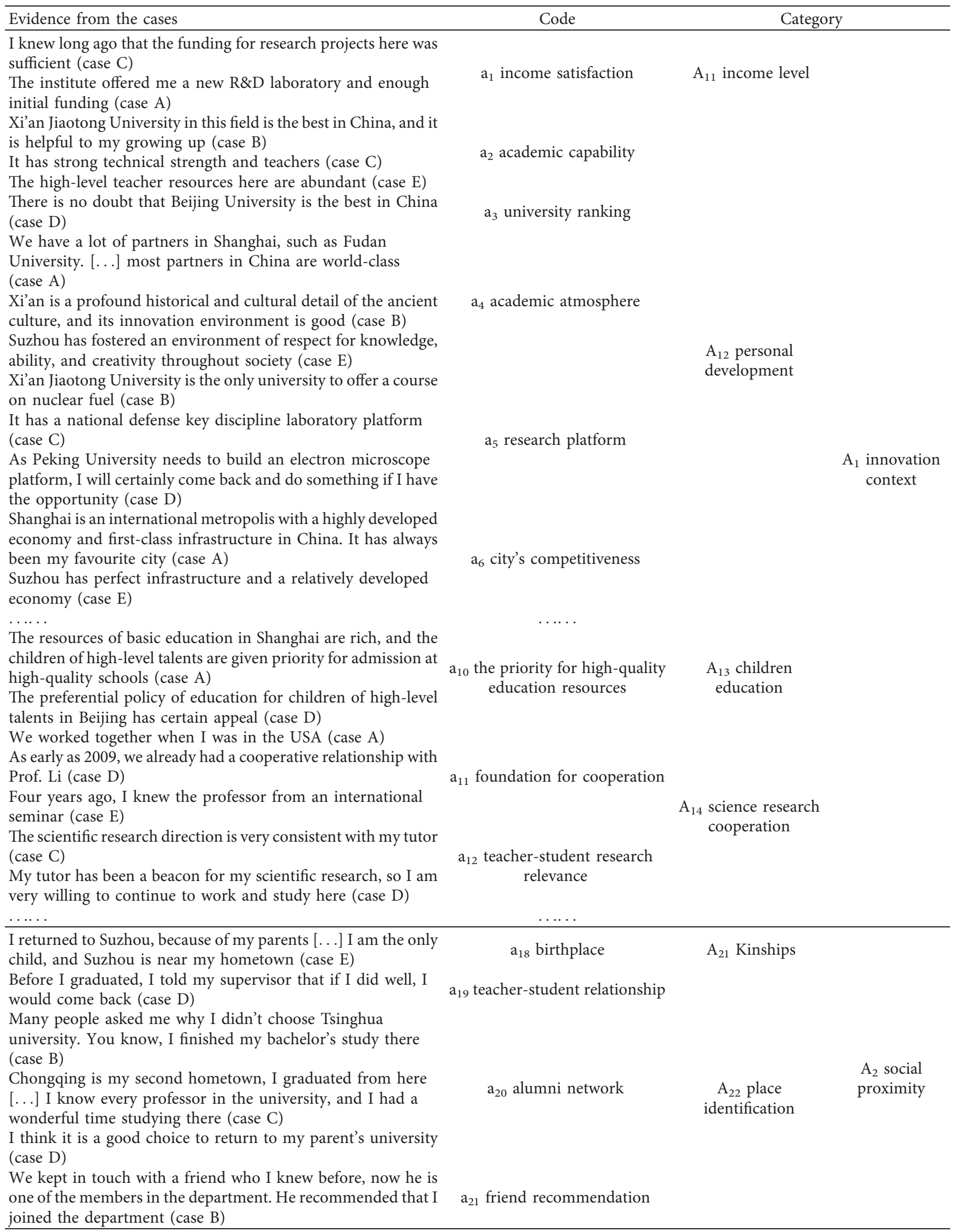




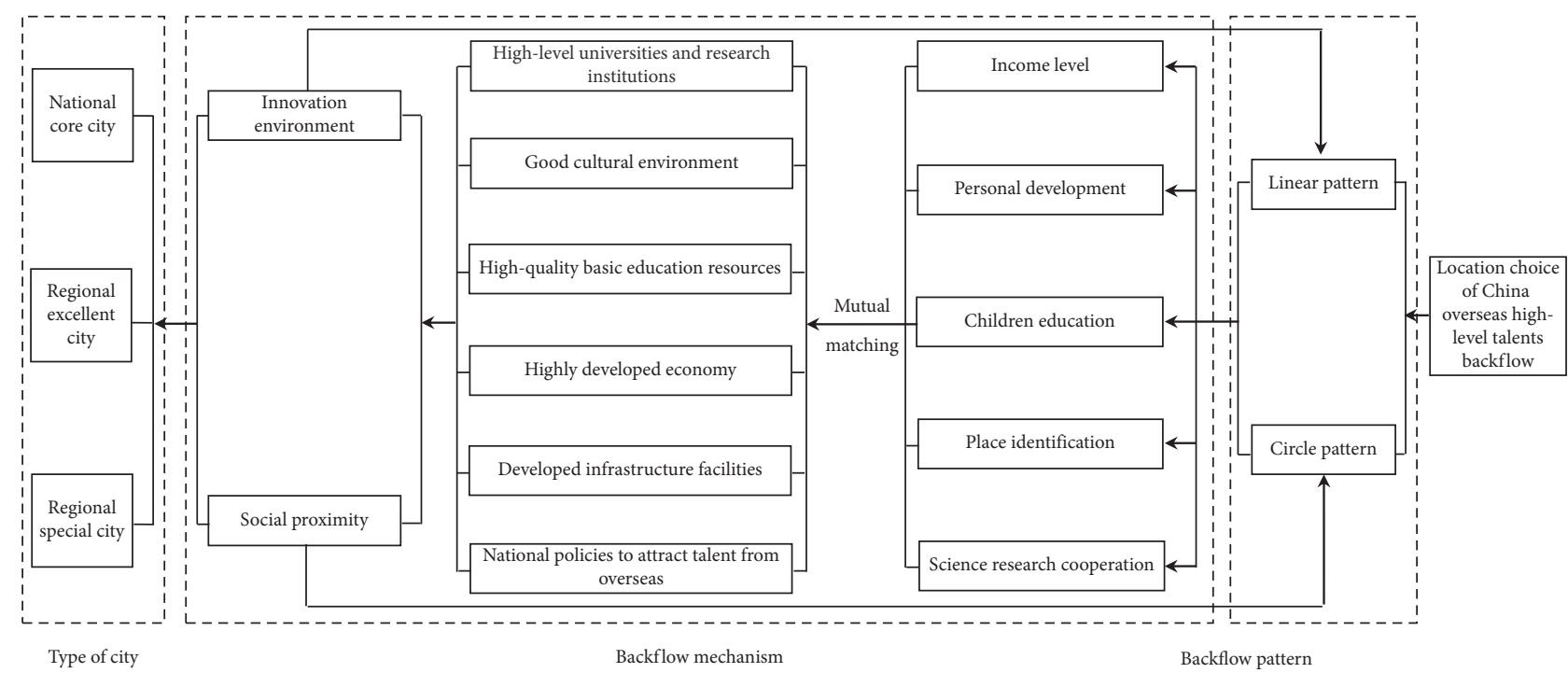

Figure 4: Backflow mechanism and location choice of high-level returned talents.

\section{Conclusion}

In examining the database for overseas high-level returned talents from Young Thousand Talents Plan during 2011-2016, the results discussed in this paper characterize important features of the spatial structure of the backflow choices of high-level talents, by focusing on the city-level locations and their driving factors. The findings indicate that the interaction between innovation context and social proximity has a direct influence on the returnee-related choice, including the city orientation and backflow pattern.

(1) In line with Ma et al. (2018), the results of the analysis confirm that high-level returned talents enhance the connectivity of Chinese cities in the world city network, which shows a significant core-peripheral structure, involving 440 city nodes, with the most important overseas regions being North America, Western Europe, Japan, Singapore, and Australia. Three types of cities driven by the relocation of China overseas highlevel talents backflow will appear: national core city (4), regional excellent city (23), and regional special city (25). The backflow path of overseas high-level talents within China, hence, presents a spatial uneven pattern as a core-peripheral structure. The main return locations are high-level cities such as municipalities or provincial capitals. Specifically, the backflow talents take seven cities as the premium return choice: Beijing, Shanghai, Wuhan, Nanjing, Hangzhou, Hefei, and Guangzhou, whose convergence proportion accounts for $71.18 \%$ during 2011-2016.

(2) Building upon the theory and empirical analysis, this paper identifies how specific factors influence location choice as well as the two main corresponding elements: innovation context and social proximity. Herein, opportunities for self-realization in academic careers are significantly important, and national core cities possessing dense research resources have objectively more favorable conditions and wider opportunities for attracting highly qualified specialists. Hence, we can infer that a large number of cities with highly overlapping innovative agglomerations, which coincides with an area with superior infrastructure and resources, might be an intended consequence to balance out the relocation tendency of some professionals in smaller cities. Moreover, personal connections and birthplace ties are shown as social proximity on the location of overseas high-level young returned talents.

(3) The paradigm about which cities will be chosen as a return location can be divided into two camps. The larger of the two camps is the backflow type, in which the talents return to a place previously familiar to them. This shows that prior experience plays a key factor in the decision-making process and the choice is mainly driven by social proximity. A smaller but growing camp is the linear route. This path places the emphasis on university prestige and its hierarchy in the China science and technology system. In the search for return targets, the core cities may generate a rather unintended magnetic field, and its knowledge endowment can push in accessing the potential decisions of high-level returned talents.

While this study provides some valuable insights into the backflow structural characteristics, several limitations should be addressed for future research. First, the empirical focus on overseas high-level returned talents involves young particularities that may affect research findings. Second, the academic field is unlike knowledge bases. This dissimilarity will affect the results of the backflow structure and backflow patterns. Future studies should focus on one subject and conduct in-depth research. Third, future studies should expand their view to other developing countries and 
integrate quantifiable data with knowledge outcomes and questionnaire information to add empirical evidence.

\section{Data Availability}

The data used in this paper are found in the database for young talents from the website http://www.1000plan.org.

\section{Conflicts of Interest}

The author has no conflicts of interest.

\section{Acknowledgments}

This research was supported by the National Natural Science Foundation of China (no. 41971160) and the Natural Science Foundation of Zhejiang Province (no. LY19D010009). Meanwhile, the author would like to thank Editage (http:// www.editage.cn) for English language editing.

\section{References}

[1] R. Florida, C. Mellander, and K. Stolarick, "Inside the black box of regional development--human capital, the creative class and tolerance," Journal of Economic Geography, vol. 8, no. 5, pp. 615-649, 2008.

[2] J. V. Beaverstock, "Re-thinking skilled international labour migration: world cities and banking organisations," Geoforum, vol. 25, no. 3, pp. 323-338, 1994.

[3] J. V. B. Verstock, "Revisiting high-waged labour market demand in the global cities: British professional and managerial workers in New York City," International Journal of Urban and Regional Research, vol. 20, no. 3, pp. 422-445, 1996.

[4] P. J. Taylor, D. R. F. Walker, G. Catalano, and M. Hoyler, "Diversity and power in the world city network," Cities, vol. 19, no. 4, pp. 231-241, 2002.

[5] Y. Liu, "Transnational mobility of the highly skilled: an review," Human Geography, vol. 28, no. 2, pp. 7-12, 2013.

[6] Y. H. D. Wei and I. Liefner, "Globalization, industrial restructuring, and regional development in China," Applied Geography, vol. 32, no. 1, pp. 102-105, 2012.

[7] D. E. Andersson, S. Gunessee, C. W. Matthiessen, and S. Find, "The geography of Chinese science," Environment and Planning A: Economy and Space, vol. 46, no. 12, pp. 29502971, 2014.

[8] A. Saxenian, "From brain drain to brain circulation: transnational communities and regional upgrading in India and China," Studies in Comparative International Development, vol. 40, no. 2, pp. 35-61, 2005.

[9] B. Karreman, M. J. Burger, and F. G. Van Oort, "Location choices of Chinese multinationals in Europe: the role of overseas communities," Economic Geography, vol. 93, no. 2, pp. 131-161, 2017.

[10] N. A. Graa, "China inc. goes global. Transnational and national networks of China's globalizing business elite," Review of International Political Economy, vol. 27, no. 2, pp. 208-233, 2020.

[11] Y. Cheng and R. LeGates, "China's hybrid global city region pathway: evidence from the Yangtze River Delta," Cities, vol. 77, pp. 81-91, 2018.

[12] A. Camenisch and B. Suter, "European migrant professionals in Chinese global cities: a diversified labour market integration," International Migration, vol. 57, no. 3, pp. 208-221, 2019.

[13] Y. Zhou, Y. Guo, and Y. Liu, "High-level talent flow and its influence on regional unbalanced development in China," Applied Geography, vol. 91, pp. 89-98, 2018.

[14] H. Ma, F. Zhang, and Y. Liu, "Transnational elites enhance the connectivity of Chinese cities in the world city network," Environment and Planning A: Economy and Space, vol. 50, no. 4, pp. 749-751, 2018.

[15] A. M. Findlay, F. L. N. Li, A. J. Jowett, and R. Skeldon, "Skilled international migration and the global city: a study of expatriates in Hong Kong," Transactions of the Institute of British Geographers, vol. 21, no. 1, pp. 49-61, 1996.

[16] M. Boyle, A. Findlay, E. Lelievre, and R. Paddison, "World cities and the limits to global control: a case study of executive search firms in Europe's leading cities," International Journal of Urban and Regional Research, vol. 20, no. 3, pp. 498-517, 1996.

[17] M. Timberlake, Y. D. Wei, X. Ma, and J. Hao, "Global cities with Chinese characteristics," Cities, vol. 41, pp. 162-170, 2014.

[18] F. Qin, "Global talent, local careers: circular migration of top Indian engineers and professionals," Research Policy, vol. 44, no. 2, pp. 405-420, 2015.

[19] B. S. A. Yeoh and S. Huang, "Introduction: fluidity and friction in talent migration," Journal of Ethnic and Migration Studies, vol. 37, no. 5, pp. 681-690, 2011.

[20] S. Maslova and R. King, "Residential trajectories of highskilled transnational migrants in a global city: exploring the housing choices of Russian and Italian professionals in London," Cities, vol. 96, pp. 102-421, 2020.

[21] H. Jiang, W. Zhang, and J. Duan, "Location choice of overseas high-level young returned talents in China," Sustainability, vol. 12, no. 21, pp. 1-16, 2020.

[22] D. Zweig and H. Wang, "Can China bring back the best? The communist party organizes China's search for talent," The China Quarterly, vol. 215, pp. 590-615, 2013.

[23] H. Bathelt and P.-F. Li, "Global cluster networks-foreign direct investment flows from Canada to China," Journal of Economic Geography, vol. 14, no. 1, pp. 45-71, 2014.

[24] J. V. Beaverstock, "Transnational elites in global cities: British expatriates in Singapore's financial district," Geoforum, vol. 33, no. 4, pp. 525-538, 2002.

[25] G. Zhang, J. Guan, and X. Liu, "The impact of small world on patent productivity in China," Scientometrics, vol. 98, no. 2, pp. 945-960, 2014.

[26] H. Kroll and I. Liefner, "Spin-off enterprises as a means of technology commercialisation in a transforming economyevidence from three universities in China," Technovation, vol. 28, no. 5, pp. 298-313, 2008.

[27] C. Chen and R. Wu, "The willingness of migrants return from overseas to develop in Shanghai and the influencing factors," Shanghai Journal of Economics, vol. 10, pp. 31-39, 2015.

[28] H. Gu, X. Meng, and T. Shen, "China's highly educated talents in 2015: patterns, determinants and spatial spillover effects," Applied Spatial Analysis and Policy, vol. 13, no. 3, pp. 631-648, 2020.

[29] J.-J. Soon, “The determinants of students' return intentions: a partial proportional odds model," Journal of Choice Modelling, vol. 3, no. 2, pp. 89-112, 2010.

[30] N. Powdthavee, "Putting a price tag on friends, relatives, and neighbours: using surveys of life satisfaction to value social relationships," The Journal of Socio-Economics, vol. 37, no. 4, pp. 1459-1480, 2008. 
[31] X. Peng, "Why does overseas Chinese talent intend to return?: a case study on the determinants of return-intentions of Chinese talent in Japan," Working Paper Series, vol. 2012-8, pp. 1-31, 2012.

[32] D. Zweig, S. F. Chung, and W. Vanhonacker, "Rewards of technology: explaining China's reverse migration," Journal of International Migration and Integration, vol. 7, pp. 449-471, 2006.

[33] X. Peng, "What makes a place attractive to returnee entrepreneurs in China?: behavior analysis on the location choices," Working Paper Series, vol. 2012-11, pp. 1-36, 2012. 